International Journal of Engineering \&Technology, $7(1.8)(2018) 204-209$
International Journal of Engineering \& Technology
SPC
Website: www.sciencepubco.com/index.php/IJET
Research paper

\title{
Observation of P-V And I-V Characteristics Before and After Partial Shadow Effect on Photovoltaic Array Using Boost Converter
}

\author{
J. Ajay Kumar , T. Sai Sourav, K.P. Prasad Rao \\ ${ }^{1}$ Department of Electrical and Electronics Engineering, Koneru Lakshmaiah Education Foundation, Vaddeswaram, Guntur, A.P. \\ ${ }^{2}$ Department of Electrical and Electronics Engineering, Koneru Lakshmaiah Education Foundation, Vaddeswaram, Guntur, A.P. \\ ${ }^{3}$ Assistant Professor, Department of Electrical and Electronics Engineering, Koneru Lakshmaiah Education Foundation, \\ Vaddeswaram, Guntur, A.P. \\ *Corresponding author E-mail: ajaykumarjagu155@gmail.com
}

\begin{abstract}
The fundamental power generation unit for photovoltaic is solar PV module. The staging of PV array pivot on environmental conditions like operating temperature, solar heatstroke, array layout. PV line-up get partial shadow effect due to shadow of trees, poles, buildings...etc. Under such conditions the array gets more complicated and it will have spare than one alp. It is very dominant to forecast the attributes of PV array under partial shadow effect to procure maximal power. More distant hotspots, discrepancy losses will occur as well as these lead to certainty and constancy problems. It is still more extortionate and difficult to get control pivot of P-V and I-V under partial shadow effect. Sun Power SPR-305-WHT-U solar panel is taken as reference and the learning cornerstone on output power peak at different solar irradiation levels. This paper also deals with the importance of bypass diodes

Keywords: Bypass diodes, Matlab /Simulink, Photovoltaic array, Partial shadow effect.
\end{abstract}

\section{Introduction}

Now a days modelling of PV arrays under non uniform conditions has become a great issue under partial shadow effect and largely investigation is done. Many algorithms are utilized to withdraw maximal power from PV line-up. Integration of MPPT with PV array is one of the method to extract maximal power [1]. Comparison of mathematical models of photovoltaic array is done based on diverse framework like high current, high electromotive force, open circuit electromotive force, short circuit current [1]. Less series resistance with single diode as well as possess unity fabrication factor is the finest classic compare to double diode model [1]. DMPPT (Distributed Maximal Potential Point Capture) is one of the method use to obtain the optimal output power from the cosmic PV panels [2]. MPPT of a cosmic scheme can be done by applying state slot balance based on linearized state equations [3]. A Continuous Quadratic Regulation scheme is proposed for cosmic scheme using state slot balance model [3]. The proposed Continuous Quadratic Regulation scheme ensures a stable system [3]. VHDL (VHSIC Hardware Description Language) is one of the method used to extract maximal potential from solar panel [4]. In this methods like Perturb and Observe (P\&O) and TPQA (Triple Point Quadratic Approximation) have been implemented and they are compared [4]. They found that the tracking time is enhanced by $90.7 \%$ in TPQA at the expense of the area [4]. A strange clone regulation scheme for a stand-in PV system using Fuzzy Logic and a Dual MPPT controller [5]. In some of the applications like buildings, curved roofs, tent, aerostats, we have to use curved thin flexible photovoltaic (FPV) module. Base on flexible photovoltaic modules, a new "Scanning Window" (SWT) is proposed to maximize the power of curved FPV modules [6]. FPV module covers up to $10^{\wedge} 8$ without any energy loss [6]. Energy from the photovoltaic is clean, available in abundance and free of cost [7]. For the extraction of maximal potential and the low voltage is boosted to high dc voltage using step up converter

The output power is compared with previous perturbation cycle which controls duty cycle of dc-dc converter [7]. DC-DC converter using MPPT controller with a Fuzzy Neutral Network (FNN) system [8]. FNN increases the tracking speed of the MPPT quickly [8]. If we consider a PV module, it will give the exact output according to the module by considering the parameters like solar irradiation temperature. The output of the module will decrease due to partial shadow effect. Partial shadow effect is nothing but which will occur on some of the modules in array or on whole array due to shadow of the trees, apartments, buildings. Generally, we will get $\mathrm{P}-\mathrm{V}$ and $\mathrm{I}-\mathrm{V}$ characteristics from the solar module. Under partial shadow effect the I-V and P-V feature arcs will decrease compare to normal conditions. If we want to analyze solar array, we have to consider single cell as reference. By doing KVL and KCL we will get some of the equations. And we can find open lap voltage (Voc), short lap current (Ish), module photocurrent $(I p h)$, reverse saturation current (Irs), maximum current (I) of the PV component. 


\section{Methods}

\subsection{Modelling of solar PV element}

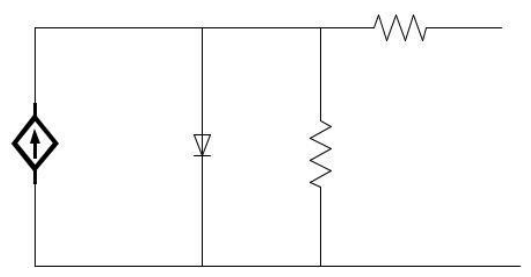

The PV solar comparable path consists of current font $I p h$ which designates the cell photon current, parallel and series resistance $R s h$ and $R s e$ respectively. Generally the value of $R s h$ is very high and $R s e$ is less. But practically they can be deserted to shorten the enquiry. Sort of PV cells in larger units called PV module, Combination of PV modules in series or parallel known as PV solar array. By applying KVL and KCL for below PV cell, we get some of the equations which are used to find the module ratings.

\subsection{Mathematical Equations}

Module photo current

$$
I p h=[I s c+K i(T-298)] * \operatorname{Ir} / 1000
$$

Where $I p h$ - solar photo current

$$
\begin{aligned}
& I S C_{\text {-short path current }} \\
& I r_{\text {-is the reverse modulation current, }}
\end{aligned}
$$

$\mathrm{Ki}$ is the cells short circuit current temperature coefficient.

$$
\operatorname{Irs}=I s c /[\exp (q V o c / N s k n T)-1]
$$

Where $\mathrm{q}$ is the electron charge, $V o c$ is the open circuit voltage, Ns is the number of cells connected in series, $\mathrm{K}$ is Boltzmann's constant, $\mathrm{T}$ is the operating temperature, $\mathrm{n}$ is the ideality factor. The inundation current Io varies with temperature given by

$$
I o=\operatorname{Irs}\left[\frac{T}{T r}\right]^{3} \exp \left[\frac{q * E g o}{n k}\left(\frac{1}{T}-\frac{1}{T r}\right)\right]
$$

Where Ego stands for band gap vigor of the semiconductor, $\mathrm{q}$ is the electron charge.

The output current of the module is given by

$$
\begin{aligned}
& I=N p * I p h-N p * I 0\left[\exp \left(\frac{v / N s+I * R s / N p}{n * V t}\right)\right] \\
& V_{T}=\frac{k * t}{q} \\
& I_{s h}=\frac{v * N_{p} / N_{s}+i * R_{s}}{R_{s h}}
\end{aligned}
$$

\section{Proposed Methodology}

\subsection{Boosting the Reduced Voltage Using Boost Convert- er with P\&O Algorithm}

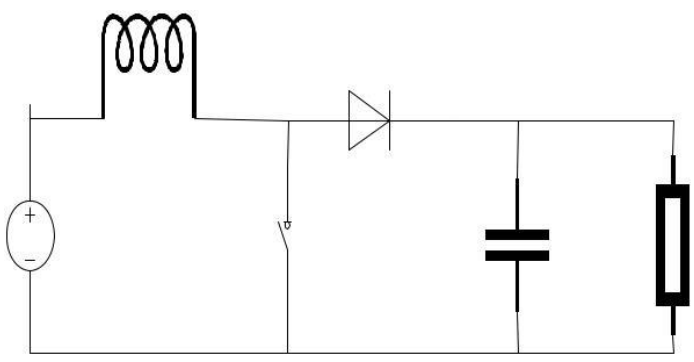

Fig.2: Boost Converter Equivalent Circuit

When the solar module is effected with partial shading the output voltage coming from each cell will reduce, then overall output power coming from the module will decrease. To overcome this issue, we can use boost converter which boosts the reduced voltage and satisfies the customer load. Basically the boost converter consists voltage source $\left(V_{s}\right)$, inductor $(\mathrm{L})$,

switch $\left(S_{W}\right)$, capacitor (C), diode (D). Boost converter is the one of the switching converter which operates periodically by opening and closing the switches. We can analyze the boost converter by applying KVL and KCL during switch on and switch off conditions. We will get the relationship between input and output.

$V_{T}=\left(\frac{V_{s}}{1-D}\right)$

Where $V_{0}$ stands for output potential of the converter, $V_{g}$ stands for input potential given to the converter, $\mathrm{D}$ is the duty ratio.

We can get the required output voltage by adjusting the duty ratio (D). Inductor value can be calculated using

$$
\begin{gathered}
L=\frac{V_{g} * D H^{\circ}}{\Delta i L} \\
C=\frac{D}{R * \frac{\Delta V_{0}}{V_{0}}}
\end{gathered}
$$

Where $\frac{\Delta V o}{V o}$ is the small change in output. Duty ratio(D) can be found by depending on input and expected output value.

\subsection{Sculpt of the Solar PV Arrangement Using Matlab Simulink}

From the six equations which we have, a solar component is established by using tag instruments in Simulink. The modules are connected in series.

\subsection{Allusion Model}

Sun Power SPR-305-WHT-U is taken as the reference component for simulation and complete parameters of component is given in below tabular column. 
Table 1: Electrical attributes data of Sun Power SPR-305-WHT-U

\begin{tabular}{|c|l|}
\hline $\begin{array}{c}\text { Case } \\
\text { Study }\end{array}$ & \multicolumn{1}{c|}{ Details } \\
\hline 1 & $\begin{array}{l}\text { No shaded module in solar PV arrangement: } \\
\mathrm{I}_{x=} 1000 \mathrm{~W} / \mathrm{m}^{\wedge} 2, \text { temperature }=25\end{array}$ \\
\hline 2 & One covered section has: $\mathbb{I}_{x=500 \mathrm{~W} / \mathrm{m}^{\wedge} 2, \text { temperature }=25}$ \\
\hline 3 & $\begin{array}{l}\text { Two modules are shaded with irradiances: } 300 \text { and } 500 \\
\mathrm{~W} / \mathrm{m}^{\wedge} 2 \text { and other have } \mathbb{I}_{x=} 1000 \mathrm{~W} / \mathrm{m}^{\wedge} 2\end{array}$ \\
\hline 4 & $\begin{array}{l}\text { Three sections are covered with irradiances: } 300,400 \\
\text { and } 500 \mathrm{~W} / \mathrm{m}^{\wedge} 2\end{array}$ \\
\hline
\end{tabular}

Table 2: Solar irradiance changes at constant temperature

\begin{tabular}{|c|c|}
\hline Case Study & Details \\
\hline 5 & $\mathbb{I}_{r=1000} \mathrm{~W} / \mathrm{m}^{\wedge} 2$, temperature $=25$ \\
\hline 6 & $\mathbb{I}_{x=1000 \mathrm{~W} / \mathrm{m}^{\wedge} 2, \text { temperature }=35}$ \\
\hline 7 & $\mathbb{I}_{x=1000 \mathrm{~W} / \mathrm{m}^{\wedge} 2, \text { temperature }=45}$ \\
\hline
\end{tabular}

Table 3: Solar irradiance changes at constant temperature

\begin{tabular}{|c|c|}
\hline Name & SPR-305-WHT-U \\
\hline Rated power & 305.226 \\
\hline Max potential & 54.7 \\
\hline Max current & 5.58 \\
\hline Open lap potential & 64.2 \\
\hline Short lap current & 5.96 \\
\hline Modules in parallel & 10 \\
\hline Modules in series & 5 \\
\hline
\end{tabular}

\section{Peturb and Observe Mppt Algorithm}

It is one of the MPPT technique which is used to trail all-out power from the panel. This method is mainly based on solar output potential and current, which acts as key to them. We know the standard conditions to get duty cycle. If there is any change in solar panel voltage or current automatically the duty cycle changes because atmospheric conditions are not all constant they vary with respect to climatic conditions. Initially $\boldsymbol{P}_{\max }$ is computed by setting the algorithm. At every intervals $V_{a c t}$ and $I_{\text {act }}$ is computed. $P_{\text {act }}$ and $P_{\max }$ comparison is done at every instant, if $P_{m \ldots}$ is greater than $P_{\operatorname{mar}}$ we have to set $P_{\text {act }}$ as new of $P_{\max }$. Hence $P_{\max }$ is the final point which delivers extreme power to the load capacity. The load impedance and input impedances should be equal to transmission of max power to the load capacity.

\subsection{Flow Chart of P\&O MPPT Algorithm}

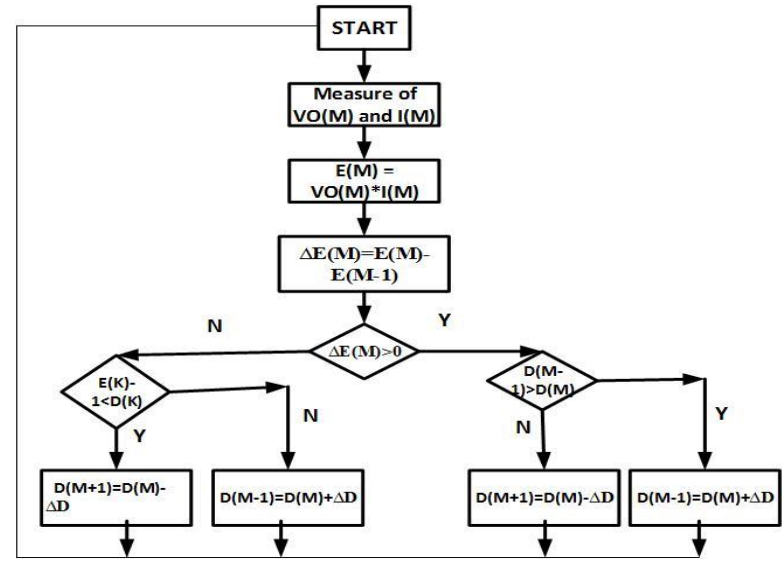

\section{Precis}

The harvest clout of the PV solar system decreases when it is partially shaded. If the integer of sheltered modules in panel rises automatically the peaks in the output clout increases. Maximal power point position is independent of varying number of shaded modules. We will get $50 \%$ of $V_{\text {oo }} \mathrm{PV}$ curves under varying solar irradiances. The output voltage curve of the boost converter depends on load, input potential of the converter. And also duty cycle plays vital role in the output curve.

\section{Design of the Converter}

The following specs are used in the procedure to design the converter, the input voltage to the converter is $93 \mathrm{v}$, switching frequency $=25 \mathrm{khz}$, output voltage $=240 \mathrm{v}$, duty ratio $=60 \%$. We know that the relationship between input and output is

$V_{0}=\frac{V_{s}}{1-D}$

From above equation by substituting Vs and Vo values, we get D $=0.6$.

The value of $\mathrm{L}$ is calculated using

$L=\frac{V_{s} * D T}{\Delta i_{L_{a}}}$

$\Delta i_{L}=10 \%$, we know that $\mathrm{T}=\frac{1}{f}, \mathrm{f}=25 \mathrm{khz}$

$\mathrm{L}=111.1 \mathrm{mH}$

The value of can be calculated using

$$
C=\left(\frac{D}{R * \frac{\Delta V_{0}}{V_{0}}}\right)
$$

already we know the value of $\mathrm{D}$, change in output voltage is $60 \%$. By substituting the values of $\mathrm{D}, \mathrm{R}$. we can find $\mathrm{C}$ value. $\mathrm{C}=$ 2000uF

Let us consider $\mathrm{R}=20 \Omega$

\section{Conclusion}

A solar PV array matlab/simulink is settled and presented in this paper. This PV array model is developed from the basic PV cell reckonings by considering the physical and environmental conditions such as temperature, shading conditions and solar irradiances. The basic six equations have each model and further more each model provides effective tool to forecast the action of the solar panel under climatic conditions. In addition to that the proposed method is used to improve the power using MPPT technique of $\mathrm{P} \& \mathrm{O}$. The gate signal of the converter is controlled through MPPT technique. And the duty ratio of the converter depends on the solar PV array output voltage and current. At $60 \%$ of duty cycle the input voltage is boosted doubled compare to input value. To avoid ripple in the output voltage the capacitor is given as very high value.

\section{Acknowledgement}

The support of the authors are thankfull through this project "Matlab/Simulink Based Modeling to Study Effect of Partial Shadow on Solar Photovoltaic Array. I want to thank all the faculty who are supported our batch for the completion of project. Specially I want to thank my guide who supports us a lot in giving ideas how to solve the problems. 


\section{References}

[1] Mathematical Modelling and Performance Evaluation of a StandAlone Polycrystalline PV Plant with MPPT.

[2] Comparison of Mathematical Models of Photo Voltaic (PV) Module and effect of various Parameters on its Performance.

[3] Analysis of the Series-Connected Distributed Maximum Power Point Tracking PV System Cheng-Wei Chen and Yaow-Ming Chen department of Electrical Engineering.

[4] Maximum Power Point Tracking of a Solar System Using State Space Averaging for Wireless Sensor Network.

[5] VHDL Implementation of Maximum Power Point Track

[6] ing algorithm

[7] Efficiency Optimization of a DSP-Based Standalone PV

[8] System Using Fuzzy Logic and Dual-MPPT Control Ah

[9] mad Al Nabulsi and Rached Dhaouadi, Senior Member,

[10] IEEE.

[11] A New Adaptive P\&O MPPT Algorithm Based on FSCC Method

[12] for Photovoltaic System.

[13] Design of DC/DC Boost Converter with FNN Solar Cell Maximum

[14] Power Point Tracking Controller

\section{Simulation Results}

\subsection{Curves at Constant Temperature and at Varied Solar Irradiances}

\section{Wield Curves in Case Study 1}
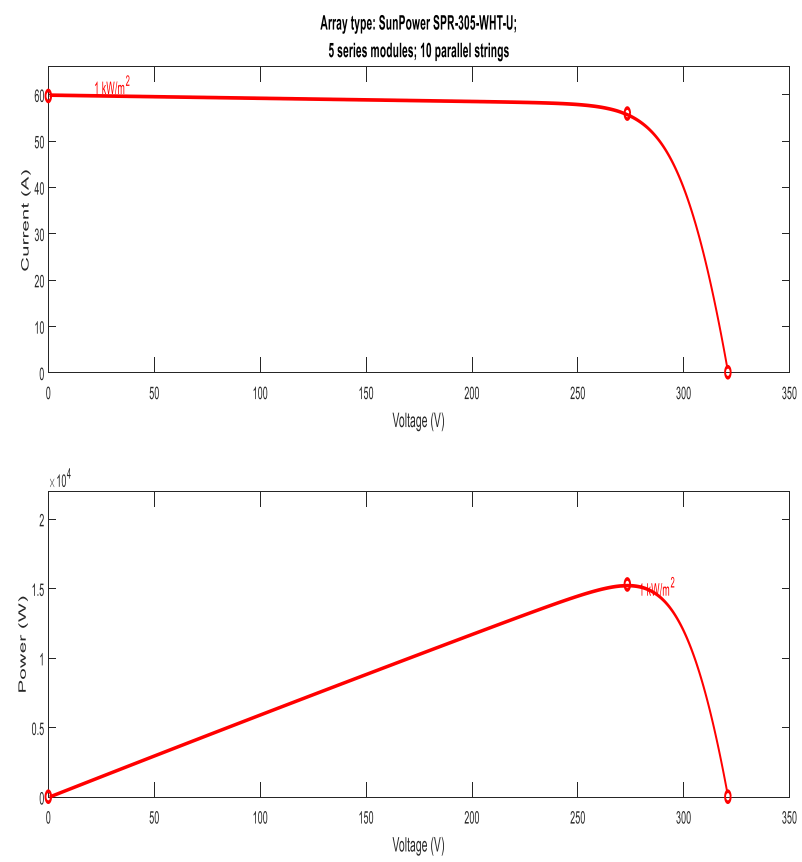

Wield Curves in Case Study 2
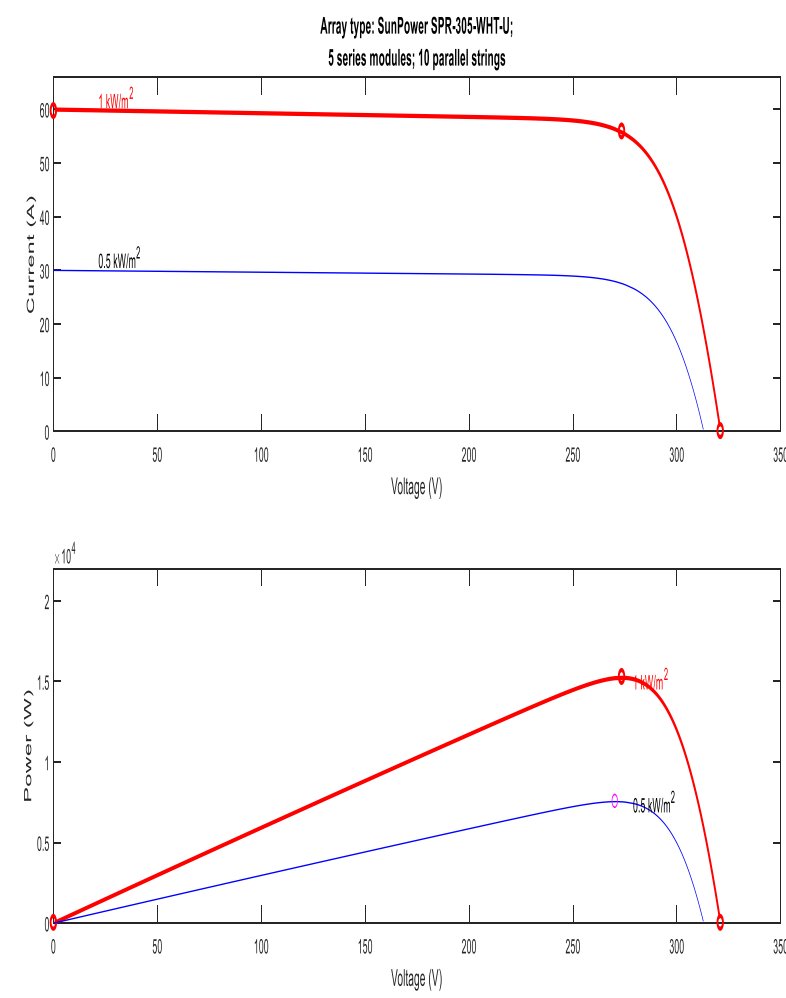

Wield Curves in Case Study 3
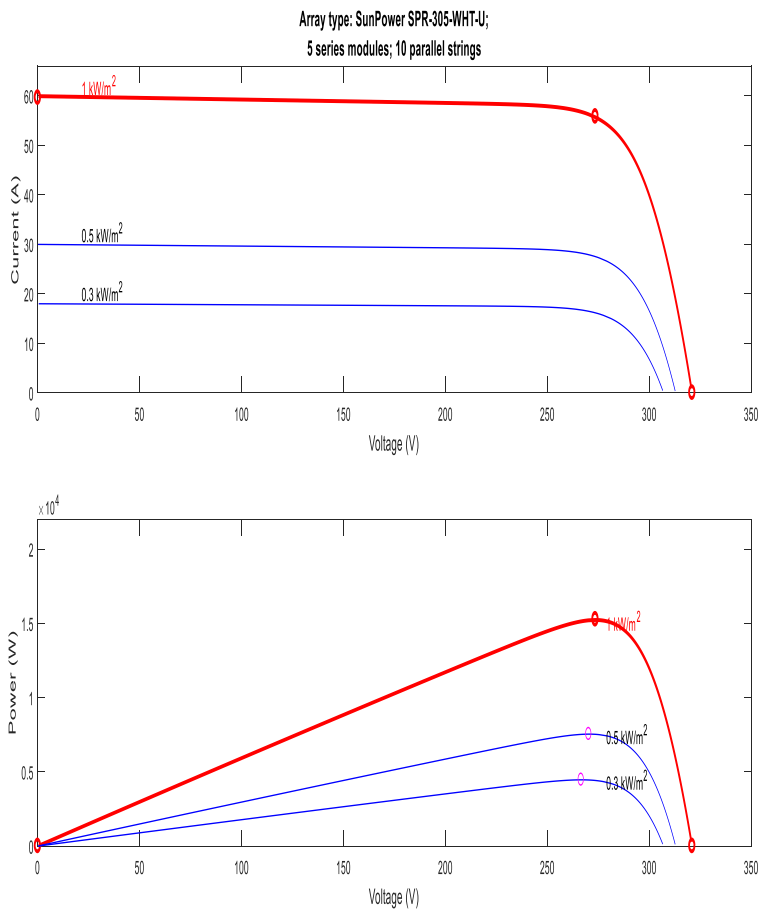

Wield Curves in Case Study 4 

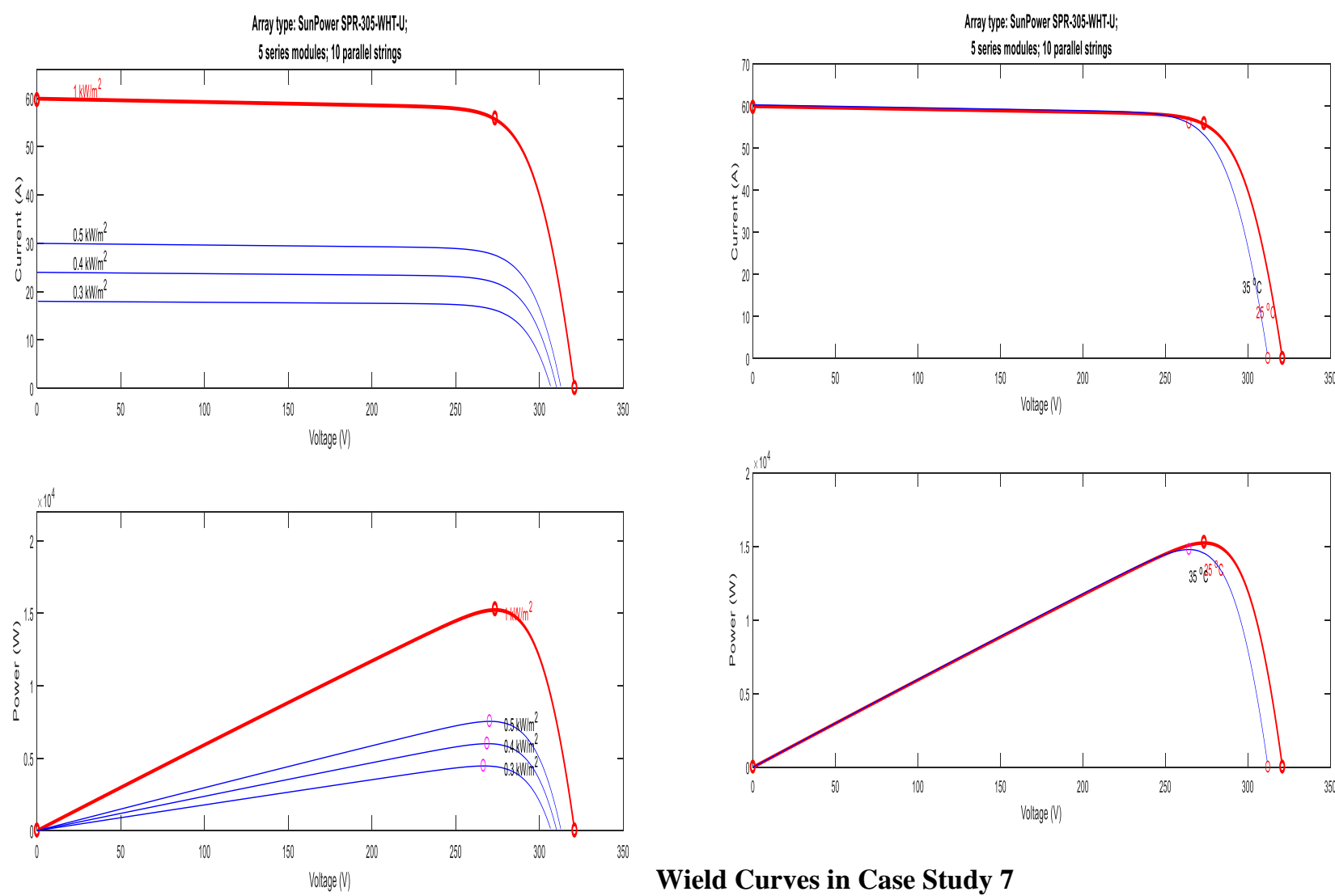

Wield Curves in Case Study 7

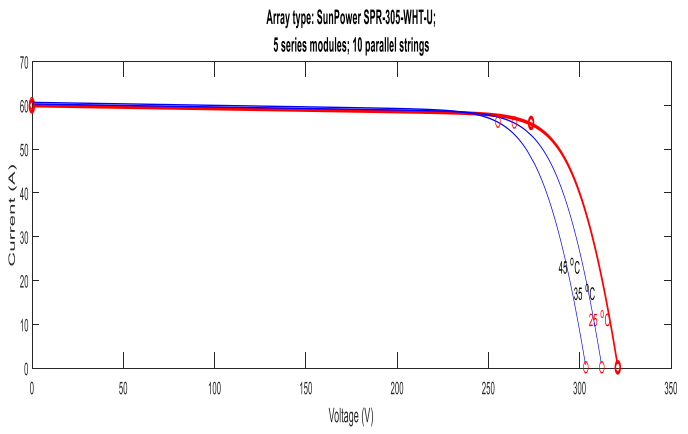

10.2 Curves at Varied Temperatures and at Constant Solar

\section{Wield Curves in Case Study 5}
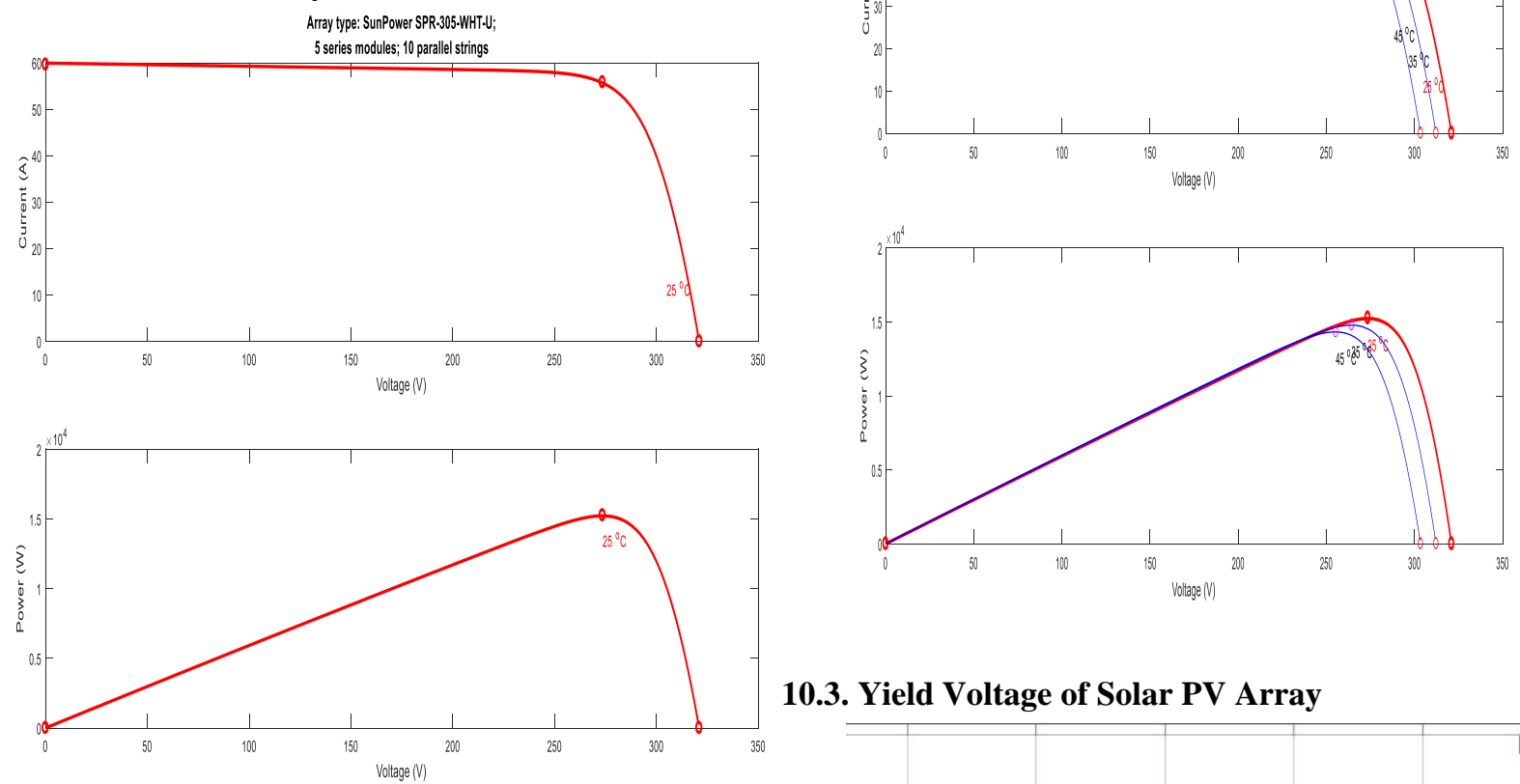

10.3. Yield Voltage of Solar PV Array

Wield Curves in Case Study 6

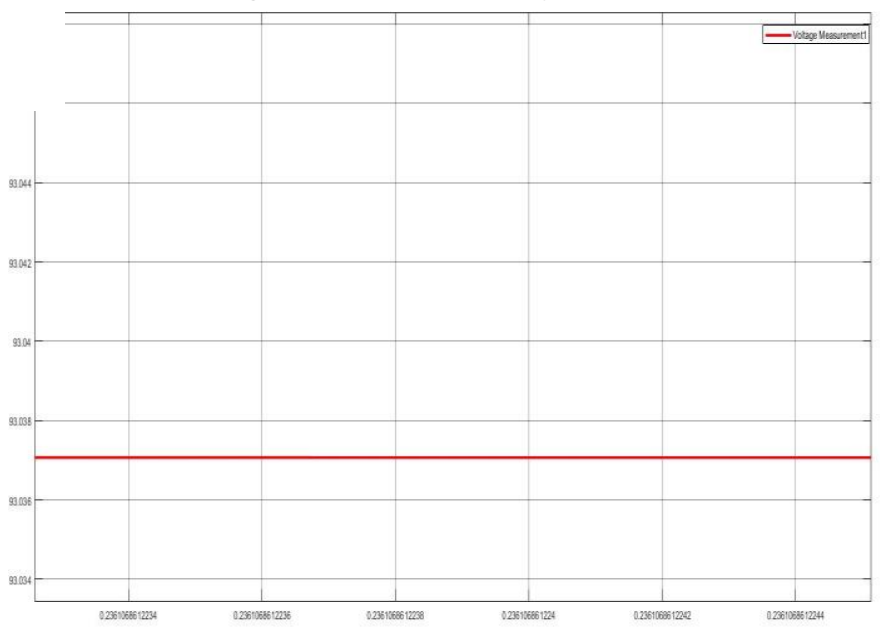




\subsection{Yield Voltage of Boost Converter}

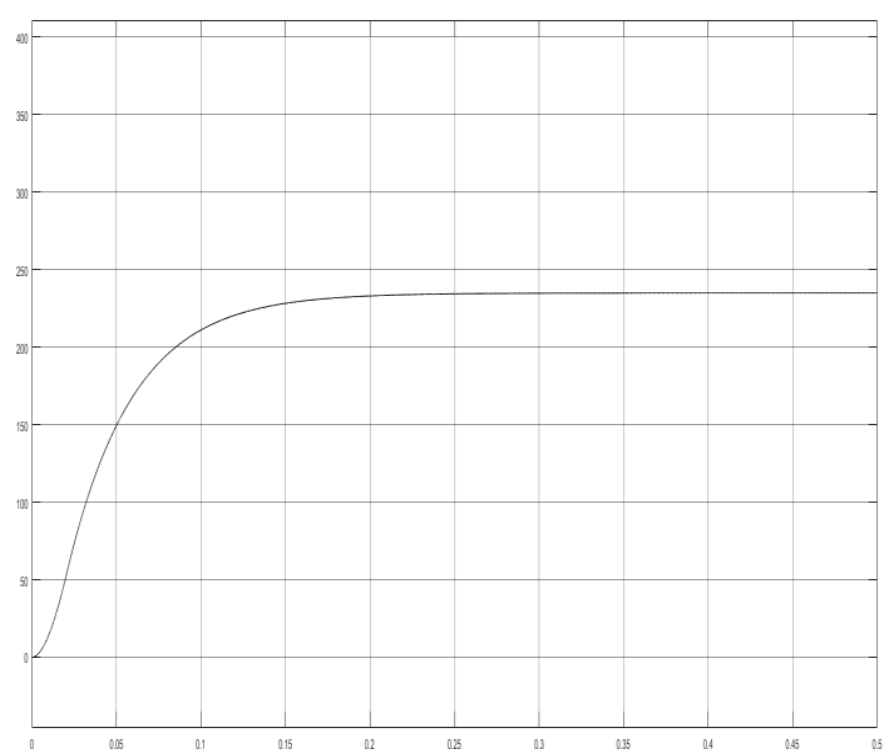

